\title{
A Review of Mobile HCI Research Methods
}

\author{
Jesper Kjeldskov and Connor Graham \\ Department of Information Systems, University of Melbourne \\ Parkville, Victoria 3010, Australia \\ jesper@cs.auc.dk,cgraham@unimelb.edu.au
}

\begin{abstract}
This paper examines and reviews research methods applied within the field of mobile human-computer interaction. The purpose is to provide a snapshot of current practice for studying mobile $\mathrm{HCI}$ to identify shortcomings in the way research is conducted and to propose opportunities for future approaches. 102 publications on mobile humancomputer interaction research were categorized in a matrix relating their research methods and purpose. The matrix revealed a number of significant trends with a clear bias towards building systems and evaluating them only in laboratory settings, if at all. Also, gaps in the distribution of research approaches and purposes were identified; action research, case studies, field studies and basic research being applied very infrequently. Consequently, we argue that the bias towards building systems and a lack of research for understanding design and use limits the development of cumulative knowledge on mobile human computer interaction. This in turn inhibits future development of the research field as a whole.
\end{abstract}

\section{Introduction}

The study of human computer interaction for mobile devices is a relatively young research field in which commercially successful devices have only been available for less than a decade and leading conferences have only a few years of history. In young research fields there is often a tendency to be highly opportunity and technology driven and to focus primarily on producing solutions while reflecting less on methodology. This characterized early computer research and can also be seen in relation to emerging research areas such as virtual and augmented reality. As a research field matures, examining how the research is being conducted and reflecting on the impact of this on the knowledge being produced is necessary in order to be able to understand and influence the future direction of the field. So far, this has not been done consistently within the community of mobile HCI and consequently little knowledge on a methodological level exists about the research field. This analysis and discussion will be borne out by this paper.

Inspired by related studies within the field of Information Systems (IS), we aim at evoking more discussion of research methodology in mobile HCI by presenting a 
snapshot of current research practice within our field, identifying and discussing shortcomings in present research and opportunities for future approaches.

Focus and reflection on research methodology has been a key subject within information system research for decades (see e.g. [1, 3, 5, 8, 11]). Facilitating this discussion, a number of frameworks for describing and categorizing IS-research methods have been developed (see e.g. [5]), which could also be relevant in relation to discussions of mobile HCI research. Specifically, we find that the classification of computeraided software engineering (CASE) research by Wynekoop and Conger [11] demonstrate a generally usable (and relatively simple) approach to informing the discussion of research methods applied within a given area. Wynekoop and Conger [11] reviewed and classified 40 IS-research papers in a two-dimensional matrix relating research methods and research purpose, providing a picture of the research field facilitating discussion of current research practice. In this paper we replicate elements from this study by applying its overall approach to the field of mobile HCI. In section 2 and 3 we present the categories of research methods and research purposes used in our classification. In section 4 we describe the conducted review of Mobile HCI research papers and present a matrix describing the resulting classification. Trends highlighted by this matrix are then discussed in section 5 and in sections 6 and 7 we indicate limitations, conclude our study and point out paths for further work.

\section{Research Methods}

Defining and especially differentiating research methods can be a challenge. Definitions are sometimes vague and often different aspects of different methods overlap. As the purpose of this paper is not to discuss definitions of research methods as such, we have chosen to apply eight definitions extracted from Wynekoop and Conger [11] with supplementary input from general references on research methodology in information systems $[7,8,9,12]$. Knowing that these definitions may themselves be objects for disagreement, we refer to $[11,5]$ for further discussion of the definitions.

Table 1. Summary of research methods (extracted from Wynekoop and Conger [11])

\begin{tabular}{|c|c|c|c|c|}
\hline & Method & Strengths & Weaknesses & Use \\
\hline \multirow[t]{3}{*}{$\begin{array}{l}\text { Natural } \\
\text { setting }\end{array}$} & $\begin{array}{c}\text { Case } \\
\text { studies }\end{array}$ & $\begin{array}{l}\text { Natural settings } \\
\text { Rich data }\end{array}$ & $\begin{array}{l}\text { Time demanding } \\
\text { Limited generalizability }\end{array}$ & $\begin{array}{l}\text { Descriptions, explanations, } \\
\text { developing hypothesis }\end{array}$ \\
\hline & $\begin{array}{l}\text { Field } \\
\text { studies }\end{array}$ & $\begin{array}{l}\text { Natural Settings } \\
\text { Replicable }\end{array}$ & $\begin{array}{l}\text { Difficult data collection } \\
\text { Unknown sample bias }\end{array}$ & $\begin{array}{l}\text { Studying current practice } \\
\text { Evaluating new practices }\end{array}$ \\
\hline & $\begin{array}{l}\text { Action } \\
\text { research }\end{array}$ & $\begin{array}{l}\text { First hand experience } \\
\text { Applying theory to practice }\end{array}$ & $\begin{array}{l}\text { Ethics, bias, time } \\
\text { Unknown generalizability }\end{array}$ & $\begin{array}{l}\text { Generate hypothesis/theory } \\
\text { Testing theories/hypothesis }\end{array}$ \\
\hline $\begin{array}{c}\text { Artificial } \\
\text { setting }\end{array}$ & $\begin{array}{l}\text { Laboratory } \\
\text { experiments }\end{array}$ & $\begin{array}{l}\text { Control of variables } \\
\text { Replicable }\end{array}$ & $\begin{array}{l}\text { Limited realism } \\
\text { Unknown generalizability }\end{array}$ & $\begin{array}{l}\text { Controlled experiments } \\
\text { Theory/product testing }\end{array}$ \\
\hline \multirow{4}{*}{$\begin{array}{l}\text { Environ- } \\
\text { ment } \\
\text { independ- } \\
\text { ent setting }\end{array}$} & $\begin{array}{c}\text { Survey } \\
\text { research }\end{array}$ & $\begin{array}{l}\text { Easy, low cost } \\
\text { Can reduce sample bias }\end{array}$ & $\begin{array}{l}\text { Context insensitive } \\
\text { No variable manipulation }\end{array}$ & $\begin{array}{l}\text { Collecting descriptive data } \\
\text { from large samples }\end{array}$ \\
\hline & $\begin{array}{l}\text { Applied } \\
\text { research }\end{array}$ & $\begin{array}{l}\text { The goal is a product which } \\
\text { may be evaluated }\end{array}$ & $\begin{array}{l}\text { May need further design to } \\
\text { make product general }\end{array}$ & $\begin{array}{l}\text { Product development, } \\
\text { testing hypothesis/concepts }\end{array}$ \\
\hline & $\begin{array}{c}\text { Basic } \\
\text { research }\end{array}$ & $\begin{array}{l}\text { No restrictions on solutions } \\
\text { Solve new problems }\end{array}$ & $\begin{array}{l}\text { Costly, time demanding } \\
\text { May produce no solution }\end{array}$ & Theory building \\
\hline & $\begin{array}{l}\text { Normative } \\
\text { writings }\end{array}$ & $\begin{array}{l}\text { Insight into firsthand } \\
\text { experience }\end{array}$ & $\begin{array}{l}\text { Opinions may influence } \\
\text { outcome }\end{array}$ & $\begin{array}{l}\text { Descriptions of practice, } \\
\text { building frameworks }\end{array}$ \\
\hline
\end{tabular}


In this section, we present and review the eight research methods used in our classification of mobile HCI research. For each method, strengths and weaknesses are identified as well as primary uses and possible application in mobile HCI research. This discussion is summarized in table 1. As an overall categorization, we group the eight research methods according to Benbasat's [2] categories of natural, artificial and environment independent settings.

\subsection{Case Studies}

Yin [12] defines a case study as "an empirical enquiry that investigates a contemporary phenomenon within its real-life context, especially when the boundaries between phenomenon and context are not clearly evident". Thus case studies are often intensive empirical studies of small size entities such as groups, organizations, individuals, systems or tools with the researcher distinct from the phenomena being studied [11]. When conducting case studies, data is typically collected by a combination of various qualitative and quantitative means such as observations, interviews and questionnaires etc. with little experimental or statistical control enforced. The data collected is grounded in natural settings, typically very rich and sometimes contradictory or inconsistent, thus often resulting in complicated analysis. Case studies are particularly well suited for research focusing on describing and explaining a specific phenomenon and for developing hypothesis or theory through, for example, applying grounded-theory approaches. However, case studies are very time demanding and generalizing findings can be difficult.

Since mobile HCI is a relatively young research area, case studies could be used to provide rich data explaining phenomena involving mobility or the use of mobile devices in context.

\subsection{Field Studies}

Generally, field studies are characterized by taking place in "the real world" as opposed to in a laboratory setting. Field studies cover a range of qualitative and quantitative approaches from ethnographic studies of phenomena in their social and cultural context inspired by the discipline of social and cultural anthropology [7] to field experiments in which a number of independent variables are manipulated [11].

Ethnographic field studies are characterized by researchers spending significant amounts of time in the field and, to some extent, immersing themselves into the environment they study. Typically, data is gathered through observations and/or interviews and the phenomena studied are placed in a social and cultural context. The major advantage of ethnographic field studies is the generation of large amounts of rich and grounded data in relatively short time. The major disadvantages are unknown biases and no guarantee of collected data being representative.

While ethnographic field studies are non-experimental, field experiments are characterized by manipulation of a number of independent variables to observe the influence on dependant variables in a natural setting. The major advantages of field experiments are increased realism and increased control in comparison to ethnographic field studies and support for studying complex situated interactions and processes. 
Disadvantages include limited control of experiments and complicated data collection compared to, for example, experiments in laboratory settings. Furthermore, as experimental manipulation increases, realism typically decreases.

In relation to mobile HCI research, field studies could be applied for either informing design for or understanding of mobility by ethnographic studies of current practice or for evaluating design or theory by conducting experiments in realistic use settings.

\subsection{Action Research}

Originating from the social sciences, action research is a well-established research method through which researchers not only apply scientific knowledge to an object of study, but also add to the body of scientific knowledge through that study, thus differentiating action research from applied science or research [8]. Conducting action research, the researcher participates in the intervention of the activity or phenomenon being studied while at the same time evaluating the results [11]. More specifically, Rapoport [9] defines action research as aiming "to contribute both to the practical concerns of people in an immediate problematic situation and to the goals of social science by joint collaboration within a mutually acceptable ethical framework".

The advantage of action research is the very close relationship between researchers and the phenomena of interest. This facilitates first-hand insight, limits researcher influence on subjects being studied and supports a prosperous way of applying theory to practice and evaluating its outcome. However, action research is very time consuming, and since the researcher takes part in the phenomena studied remaining objective can be difficult. Also, when participating in the intervention of an activity or phenomenon, considerations emerge concerning if it is ethically acceptable for a researcher, for example, to conceal knowledge of particular approaches having better effects than others. Finally, the outcome of this research can be difficult to generalize.

In relation to mobile $\mathrm{HCI}$ research, action research could be used for extending field or case studies by researchers participating actively in real world activities involving mobility, introducing different solutions or theories "on-the-fly" as well as evaluating their effects and/or validity.

\subsection{Laboratory Experiments}

In contrast to field studies, laboratory studies are characterized by taking place in a controlled environment created for the purpose of research. Thus laboratory experiments do not necessarily have to take place in dedicated "laboratories" as such but can be conducted in various controlled environments such as in an office [10], in a hallway [4] or in a simulator [6]. Laboratory experiments facilitate various types of data being collected using different experimental methods depending on the style of subsequent analysis desired. While traditional quantitative measurements of factors such as error rate and task completion times collected through, for example, cognitive walkthrough methods are suitable for statistical methods of analysis, using more qualitative approaches such as heuristic evaluation or think-aloud protocols during the conduct of experimental tasks also produces results suitable for analysis. 
The major advantages of laboratory studies are the opportunity to focus on specific phenomena of interest and a large degree of experimental control in terms of manipulation of variables before and during the experiment through for example assignment of test subjects and exposure to different treatment variables [11]. Also, laboratory experiments are typically highly replicable and facilitate good data collection. Disadvantages include limited relation to the real world and an unknown level of generalizability of results outside laboratory settings.

In mobile HCI research, laboratory experiments are suitable for evaluating design ideas, specific products or theories about design and user interaction in controlled environments with little or no interference from the real world.

\subsection{Survey Research}

Surveys usually inform research by providing information from a known sample of people gathered through various systematic techniques such as questionnaires and interviews. Using surveys, data is gathered directly from selected respondents and it is assumed that these are independent of their environment [11]. Typically, data from questionnaire surveys is collected without researcher intervention and is analyzed quantitatively while data from interview surveys are analyzed qualitatively.

The major advantages of surveys are that they facilitate large amounts of data to be gathered with relatively little effort, supporting broad generalization of results. Also a high level of control regarding sample subjects makes reduction of bias possible thus increasing validity. However, surveys suffer from providing only snapshots of studied phenomena and rely highly on the subjective views of respondents.

In mobile HCI research, surveys could, for example, facilitate generalizable information being gathered about user needs and requirements for understanding a phenomenon, building theory or developing systems. Also, surveys could be used for gathering data about the user experience of specific products or designs for evaluation purposes.

\subsection{Applied Research}

According to [11] applied research, builds on trial and error on the basis of the researchers capabilities of reasoning through intuition, experience, deduction and induction. Typically the desired goal or outcome of the research process is known in terms of requirements on some level of abstraction, but methods or techniques for accomplishing this outcome are unknown and thus sought through applying potentially relevant research. The advantages of applied research is that it is very goal directed and (typically) results in some kind of product being produced, which can be evaluated against the initial goals. The major disadvantages of applied research are that initial solutions may be very limited and not generalizable and that appropriate solutions for accomplishing the desired outcome may not be produced at all.

In mobile HCI research, applied research is relevant in relation to design and implementation of systems, interfaces and techniques, which meet certain requirements for performance, user interaction, user satisfaction etc. 


\subsection{Basic Research}

Doing basic research, researchers develop new theories or study well-known problems to which neither specific solutions nor methods for accomplishing solutions are known [11]. Like applied research, the approach of basic research is trial and error based relying on the competences of the researcher. The major advantage of basic research is the openness of the research facilitated both in terms of approaches and time, allowing a high level of creativity in the search for methods and solutions. However, basic research, like applied research, can be very time consuming and there is no guarantee of any solution eventually being produced.

In relation to mobile HCI, basic research may be applied to the development of theoretical frameworks for, for example, understanding basic issues of mobility or for identifying new problems and possible solutions related to human-computer interaction while being mobile.

\subsection{Normative Writings}

In order to include the significant body of so-called "non-research" writings about phenomena of interests in their classification of research methods, Wynekoop and Conger [11] suggests the category of normative writings, covering concept development writings, presentation of "truth" and Benbasat's [3] category of "application descriptions". While concept development writings organize ideas in order to stimulate and indicate directions for future research, such as the case of this paper, normative writings belonging to the "truth" category present ideas, concepts and suggestions, which seem intuitively correct but are not based on theory or research. Application descriptions are defined as "narratives written by practitioners" [11], describing subjective views on a situation and what worked for them in that particular situation. The primary advantage of normative writings is that they require little effort to produce compared to presenting complex theoretical concepts. Disadvantages include limited theoretical and methodological reflection and limited generalizability.

In mobile $\mathrm{HCI}$, normative writings describing designs and processes that worked well or did not prove successful may be useful for inspiring future research or design.

\section{Research Purpose}

Research methods as discussed above and research purpose are typically closely related but not necessarily determined by one another. Like Wynekoop and Conger [11] we thus use the second dimension of our matrix for classifying mobile $\mathrm{HCI}$ research to describe research purpose. Populating the categories this dimension we borrow the categories and definitions of research purposes originally proposed in [1] and also used in [11]. These are briefly defined below.

Understanding is the purpose of research focusing on finding the meaning of studied phenomena through e.g. frameworks or theories developed from collected data. 
Engineering is defined as the purpose of research focused towards developing new systems or parts of systems such as e.g. an interaction technique for mobile phones.

Re-engineering describes the purpose of research focusing on improving existing systems by redeveloping them such as e.g. adapting a web browser to a small display.

Evaluating is the purpose of research assessing or validating products, theories or methods e.g. the usability of a specific mobile device design or a theory of interaction.

Describing finally refers to research focusing on defining desirable properties of products e.g. a mobile system.

\section{Classification of Mobile HCI Research}

In this section we present a classification of selected mobile human-computer interaction research papers in relation to the research methods and purposes discussed above.

A total of 102 conference and journal papers were classified in relation to the described categories of research purpose and research methods applied. These papers constitute all publications related to mobile human-computer interaction between 2000 and 2002 in the following top-level conference proceeding series and journals:

- Conference on Computer-Human Interaction, CHI, ACM

- Conference on Advanced Visual Interfaces, AVI, ACM

- Conference on User Interface Software and Technology, UIST, ACM

- Conference on Computer-Supported Cooperative Work, CSCW, ACM

- Symposium on Human-Computer Interaction with Mobile Devices, Mobile HCI

- Symposium on Designing Interactive Systems, DIS, ACM

- Transactions on Computer-Human Interaction, TOCHI, ACM

- Journal of Personal and Ubiquitous Computing, Springer-Verlag

While other conferences and journals exist, presenting interesting research on mobile human-computer interaction, we found that the listed conferences and journals provided a solid and adequately representative base for this study given the number of publications on the topic and the general level of the reviewing processes for these conferences and journals.

The 102 papers specifically focusing on mobile human-computer interaction were identified by thoroughly reading through abstracts (and sometimes introductions) of all publications between 2000 and 2002 in the listed conference proceeding series and journals. A paper was selected for the study if it was in any way related to mobile devices and human-computer interaction. Thus a paper would be omitted if it focused only on mobile network protocol design or did not involve any aspect of mobility of users or systems. All papers were printed, numbered, read through and classified over a period of two weeks by the first author of this paper with particular focus on identifying the purpose of the presented work and the research methods applied in achieving this. The classification is shown in table 2 below. 
Table 2. Classification of mobile human-computer interaction research. Numbers refer to indexes in the appendix of reviewed mobile HCI research papers bibliography

\section{Research Method}

\begin{tabular}{|c|c|c|c|c|c|c|c|c|}
\hline & $\begin{array}{l}\text { Case } \\
\text { studies }\end{array}$ & $\begin{array}{c}\text { Field } \\
\text { studies }\end{array}$ & $\begin{array}{c}\text { Action } \\
\text { research }\end{array}$ & $\begin{array}{c}\text { Lab } \\
\text { experiment }\end{array}$ & $\begin{array}{c}\text { Survey } \\
\text { research }\end{array}$ & $\begin{array}{l}\text { Applied } \\
\text { research }\end{array}$ & $\begin{array}{c}\text { Basic } \\
\text { research }\end{array}$ & $\begin{array}{c}\text { Normative } \\
\text { writings }\end{array}$ \\
\hline$\overline{\text { Understand }}$ & $10,11,51$ & $\begin{array}{l}67,68, \\
69,101\end{array}$ & & 91 & $\begin{array}{l}14,25 \\
53,72\end{array}$ & $\overline{43}$ & $1,21,32$ & 16,20 \\
\hline Engineer & 24,49 & $\begin{array}{c}3,65,71, \\
85,94\end{array}$ & & & & $\begin{array}{c}2,4,9,12, \\
17,18,19, \\
23,27,28, \\
29,33,34, \\
36,38,39, \\
41,45,46, \\
48,50,52, \\
57,58,59, \\
60,64,70, \\
73,74,76, \\
77,78,79, \\
81,83,84, \\
86,89,90, \\
92,93,95, \\
97,98\end{array}$ & & \\
\hline $\begin{array}{c}\text { Re- } \\
\text { engineer }\end{array}$ & 22 & & & & & $\begin{array}{c}7,8,31 \\
55,63,75 \\
80,100 \\
102\end{array}$ & & \\
\hline Evaluate & & $\begin{array}{c}6,9,41, \\
63,71,81, \\
85,89\end{array}$ & & $\begin{array}{c}4,5,6,7, \\
8,9,12, \\
13,18,22, \\
30,40,42, \\
44,49,50, \\
55,56,58, \\
60,61,66, \\
75,77,82, \\
90,94,97, \\
98,99\end{array}$ & $\begin{array}{l}26,33, \\
64,93\end{array}$ & & & \\
\hline Describe & & $47,62,96$ & & 47 & & 35 & & $\begin{array}{c}15,37,54, \\
87,88\end{array}$ \\
\hline
\end{tabular}

To ensure consistency, the initial classification of the papers was evaluated by scanning through all the papers a second time on a single day. To ensure validity, the second author of this paper subsequently evaluated the classification by blindly classifying 20 randomly selected papers. As this resulted in a number of disparities, all 102 papers were discussed and classified one by one through the collaboration of the two authors.

While in the review presented in Wynekoop and Conger [11] each paper is only attributed to one research method and purpose, this was not possible with all of the papers on mobile human-computer interaction. Some of the reviewed papers clearly employed more than one research method and had multiple purposes. A common example of this would be papers presenting a system engineered by applying research and subsequently evaluated in a laboratory. Consequently, such papers were given multiple classifications and appear more than once in table 2 above. As a consequence of multiple research methods and purposes in the same paper, aggregate percentages will sometimes amount to more than $100 \%$. 
Table 2 shows that $55 \%$ of mobile HCI research falls within the applied category (56 of 102 papers). The secondly most used method is laboratory experiments being applied in $31 \%$ of the research (32 of 102 papers). $20 \%$ of the papers report from field studies and $8 \%$ report from survey studies while $7 \%$ are normative writings and $6 \%$ report from case studies. Only 3 papers were classified as basic research and no entries were found for action research. This distribution shows a clear bias towards environment independent and artificial setting research in the form of applied and laboratory based approaches at the expense of natural setting research focusing on real use and basic and action research generating theory and refining it in practice.

Looking at the research purpose, 51\% of mobile HCI research is done for engineering with additional $10 \%$ done for re-engineering. Thus in total, $61 \%$ of the research reported involves building systems. $41 \%$ of the papers involve evaluation, of which $71 \%$ is done through laboratory experiments $19 \%$ through field experiments and the remaining $10 \%$ through surveys. Research for understanding mobile HCI accounts for $18 \%$ of the papers, of which $22 \%$ reports from the use of surveys and $22 \%$ from field studies. Describing different aspects of mobile HCI accounts for $10 \%$ of the research, of which $50 \%$ are in the form of normative writings. Thus within mobile HCI research there is a clear tendency towards building systems and if evaluating them, doing so in laboratory settings. Understanding and learning from the design and real use of systems is less prioritized, limiting the generation of a cumulative body of knowledge on mobile human-computer interaction.

Of the 56 papers applying research, $96 \%$ do so for the purpose of engineering or reengineering. Thus in total, these two cells in the matrix account for more than $50 \%$ of the mobile HCI research classified. Of the 32 papers in the laboratory experiment category, 94\% use this method for evaluation purposes. Of the 20 papers reporting from field studies, $40 \%$ use this method for evaluation purpose while $25 \%$ use it for engineering. $20 \%$ ( 4 papers) report from field studies for the purpose of understanding. Thus when building systems within mobile HCI research, there is a clear tendency to do so primarily by trial and error and a lesser tendency to do so based on actual user studies. Also, controlled environments are used primarily for product evaluation purposes. Field studies are only applied to inform the design of new systems to a limited extend.

Of the 45 papers reporting applied research with the purpose of engineering systems, only $37 \%$ (17 papers) also report evaluating the produced solutions. $61 \%$ of these evaluations are done through laboratory experiments, $22 \%$ through field studies and the remaining $17 \%$ by surveys. Of the 9 papers reporting the re-engineering of systems, $56 \%$ also report evaluations of these systems. $80 \%$ of these are through laboratory experiments and $20 \%$ through field studies. Thus when building new systems, there is a tendency towards not evaluating them while when subsequently re-building them, evaluation is more prevalent. When evaluating engineered or re-engineered systems, there is a large bias towards applying laboratory-based approaches. 


\section{Discussion}

Table 2 reveals a lack of focus on real use contexts in relation to engineering and evaluating mobile systems as well as limited construction and use of theory. While field studies are being done, natural setting research is not prevalent. One reason for this may be that applied research and laboratory experiments are simply easier to conduct and manage than field studies, case studies and action research. Another reason may be that mobile HCI has strong roots in computer science and humancomputer interaction. These fields collectively have a strong bias towards engineering and evaluating systems, with input from fields such as ethnography only recently emerging.

Reflecting further on table 2, a number of features seem to characterize the field of mobile human-computer interaction. Firstly, given the prevalent applied approach to engineering it seems assumed that we already know what to build and which specific problems to overcome such as limited screen real estate, limited means for interaction, dynamic use-contexts and limited network bandwidth. As only a little research actually addresses the question of what is useful and what is perceived problematic from a user-perspective and as a qualitative review of the classified papers reveal that evaluations are often focused on functionality rather than contextual issues, it is difficult to set aside this assumption and identify and face more fundamental challenges to mobile human-computer interaction. Secondly, given the limited focus on real-world studies it seems that the real contexts are not actually important for the mobile system we build and use and that mobile computer systems are a generically applicable solution. The view that building and evaluating systems by trial and error is better than grounding engineering, evaluation and theory in user-based studies weakens research in mobile HCI. Thirdly, given the fact that only few studies are based on a methodological foundation, it seems assumed that methodology matters very little in mobile HCI research. This supposition is problematic as the choice of methods clearly has influence on the results subsequently produced [8]. From a cognitive psychology perspective, for example, problem solving by applied research is viewed as a rather poor method as it demands huge efforts by researchers that often "translate into poor performance because they require search of a large space of possibilities" [11].

The distribution of research methods and purposes shown in table 2 offers a number of opportunities in the area of mobile HCI. Firstly, the fact that field studies are mostly being used for the purpose of evaluation presents the opportunity to use this method to explore use context and user needs to promote understanding. Field studies could assist with the translation of needs into new designs and the re-engineering of existing designs. Mobility is very difficult to emulate in a laboratory setting, as is the dynamism of changing context. Field studies offer the ideal opportunity for the study of rich real-world use cases. Learning from other disciplines that have struggled with the study of similar "slippery" phenomena, such as ethnography in this regard could provide important insight. The lack of survey and case study research also presents an opportunity. Information Systems uses these approaches widely, with the former research method often being used to collect large amounts of data from, for example, actual end-users of a system. In addition this approach offers a good opportunity to study the use of systems in the hands of a large segment of the population, enabling 
wider reaching generalizations. Case studies within mobile HCI could increase learning from existing implemented systems within real-world contexts, for example mobile systems and infrastructure within organizations. Such case studies would enable the close scrutiny of pre-defined phenomena in fixed contexts, which could then be used to enrich the collective knowledge in the discipline and to enable key issues to be described and understood. The issues generated could then be used to generate hypotheses to propagate further research. The limited use of action research points to both the lack of a well-established body of theoretical research within the discipline and the unwillingness to implement mobile systems which are uncertain to succeed and take a long time to evaluate and implement. This is perhaps not surprising, given the current cost of such technology and the associated implementation overhead. Nonetheless, this is, again, an opportunity to develop knowledge in the discipline through practice and evaluation. Finally, the lack of basic research means that opportunities exist for the development of theoretical frameworks to promote description and understanding. In addition, the applicability of theories from other disciplines to mobile HCI can be examined through basic and action research.

\section{$6 \quad$ Limitations}

The presented review of research methods has a number of limitations. First of all, the categories of research methods can be criticized for being vague and overlapping. Thus for example, case studies are often done in the field but it is unclear how this method differs from field studies. If a case study were, on the other hand, conduced in a controlled environment, how would it be different from a laboratory experiment? Furthermore, it can be discussed whether the eight categories of methods belong to the same level of abstraction or if some categories could be subordinated others. Combined with the fact that many research papers provide only little information about method, it can be difficult to decide which category a specific paper belongs to. Thus the presented study relies on the researchers comprehension of the categories and ability to make a qualified judgment on the basis of sometimes scarce information. Also, it can, of course, be questioned if the selected papers are representative and to what extent activities within a given area are actually reflected through publications.

\section{Conclusions}

In this paper we have examined and reviewed research methods within the field of mobile HCI through classifying 102 research papers. We have identified a number of significant trends in research purpose and methods with a clear bias towards engineering systems using applied approaches and, if evaluating them, doing so in laboratory settings. In addition we have found that research methods examining phenomena in context such as case studies are not widely used. These findings present a number of opportunities for further research suggesting the need for a change of emphasis within the field of mobile HCI. 


\section{References}

[1] Basili, V.R., Selby, R.W. and Hutchins, D.H.: Experimentation in software engineering. IEEE Transactions on Software Engineering, SE-12 (1986) 733743

[2] Benbasat, I.: An analysis of research methodologies. In MacFarlan, F.W. (Ed.) The Information System Research Challenge. Boston, Harvard Business School Press (1985) 47-85

[3] Benbasat, I., Goldstein, D.R. and Mead, M.: The case research strategy in studies of information systems. MIS Quarterly, Vol. 7(3) (1987) 369-386.

[4] Bohnenberger, T., Jameson, A., Kruger, A. and Butz, A.: Location-Aware Shopping Assistance: Evaluation of a Decision-Theoretic Approach. In Proceedings of Mobile HCI 2002, Pisa, Italy, Springer-Verlag, Berlin (2002)

[5] Galliers, R.D.: Choosing Appropriate Information Systems Research Approaches: A Revised Taxonomy. In Proceedings of the IFIP TC8 WG 8.2 Working Conference on The Information Systems Research Arena of The 90's, Copenhagen, Denmark (1990)

[6] Kjeldskov J. and Skov M. B. (2003) Evaluating the Usability of a Mobile Collaborative System: Exploring Two Different Laboratory Approaches. In Proceedings of the 4th International Symposium on Collaborative Technologies and Systems 2003. Orlando, Florida.

[7] Lewis, I.M.: Social Anthropology in Perspective. Cambridge University Press (1985)

[8] Myers, M.D.: Qualitative Research in Information Systems. MIS Quarterly, Vol. 21(2) (1997) 241-242

[9] Rapoport, R.N.: Three Dilemmas in Action Research. Human Relations, Vol. 23(4) (1970) 499-513

[10] Tang, J., Yankelovich, N., Begole, B., Van Kleek, M., Li, F. and Bhalodia, J.: ConNexus to Awarenex: Extending awareness to mobile users. In proceedings of CHI2001, Seattle, WA, USA, ACM (2001)

[11] Wynekoop, J.L. and Conger, S.A.: A Review of Computer Aided Software Engineering Research Methods. In Proceedings of the IFIP TC8 WG 8.2 Working Conference on The Information Systems Research Arena of The 90's, Copenhagen, Denmark (1990)

[12] Yin, R. K.: Case Study Research, Design and Methods, 2nd ed. Newbury Park, Sage Publications (1994)

\section{Appendix: Reviewed Mobile HCI Research Papers, 2000-2002}

[1] Abowd, G.D. and Mynatt, E.D.: Charting Past, Present and Future Research in Ubiquitous Computing". ACM Transactions on Computer-Human Interaction, Vol. 7, No. 1 (2000) 29-58

[2] Beigl, M.: MemoClip: A Location-Based Remembrance Appliance. Personal and Ubiquitous Computing, Vol. 4. Springer-Verlag, London (2000) 230-233 
[3] Bertelsen, O. and Nielsen, C.: Augmented Reality as a Design Tool for Mobile Devices. In proceedings of DIS 2000, ACM (2000)

[4] Bohnenberger, T., Jameson, A., Kruger, A. and Butz, A.: Location-Aware Shopping Assistance: Evaluation of a Decision-Theoretic Approach. In Proceedings of Mobile HCI 2002, Pisa, Italy, Springer-Verlag, Berlin (2002)

[5] Brewster, S. and Murray, R.: Presenting Dynamic Information on Mobile Computers. Personal and Ubiquitous Computing, Vol. 4. Springer-Verlag, London (2000) 209-212

[6] Brewster, S.: Overcoming the Lack of Screen Space on Mobile Computers. Personal and Ubiquitous Computing, Vol. 6. Springer-Verlag, London (2002) 188-205

[7] Buyukkokten, O., Garcia-Molina, H., Paepcke, A. and Winograd, T.: Power Browser: Efficient Web Browsing for PDAs. In Proceedings of CHI2000, The Hague, Amsterdam, ACM (2000)

[8] Buyukkokten, O., Garcia-Molina, H., Paepcke, A.: Accordion Summarization for End-Game Browsing on PDAs and Cellular Phones. In proceedings of CHI2001, Seattle, WA, USA, ACM (2001)

[9] Cheverst, K., Davies, N., Mitchell, K., Friday, A. and Efstratiou, C.: Developing a Context-aware Electronic Tourist Guide: Some Issues and Experiences. In Proceedings of CHI2000, The Hague, Amsterdam, ACM (2000)

[10] Cheverst, K., Mitchell, K. and Davies, N.: Investigating Context-aware Information Push vs. Information Pull to Tourists. In Proceedings of Mobile HCI 2001, Lille, France (2001)

[11] Cheverst, K., Davies, N., Mitchell, K. and Efstratiou, C.: Using Context as a Crystal Ball: rewards and Pitfalls. Personal and Ubiquitous Computing, Vol. 5. Springer-Verlag, London (2001) 8-11

[12] Chincholle, D., Goldstein, M., Nyberg, M. and Eriksson, M.: Lost or Found? A Usability Evaluation of a Mobile Navigation and Location-Based Service. In Proceedings of Mobile HCI 2002, Pisa, Italy, Springer-Verlag, Berlin (2002)

[13] Chittaro, L. and Cin, P.D.: Evaluating Interface Design Choices on WAP Phones: Single-choice List Selection and Navigation among Cards. In Proceedings of Mobile HCI 2001, Lille, France (2001)

[14] Colbert, M.: A Diary Study of Rendezvousing: Group Size, Time, Pressure and Connectivity. In Proceedings of Mobile HCI 2002, Pisa, Italy, Springer-Verlag, Berlin (2002)

[15] Constas, I. and Papadopoulos, D.: Interface-Me: Pursuing Sociability Through Personal Devices. Personal and Ubiquitous Computing, Vol. 5. SpringerVerlag, London (2001) 195-200

[16] Coschurba, P., Baumann, J., Kubach, U. and Leonhardi, A.: Metaphors and Context-Aware Information Access. Personal and Ubiquitous Computing, Vol. 5. Springer-Verlag, London (2001) 16-19

[17] Danesh, A., Inkpen, K., Lau, F., Shu, K. and Booth, K.: Geney: Designing a Collaborative Activity for the Palm Handheld Computer. In proceedings of CHI2001, Seattle, WA, USA, ACM (2001) 
[18] De Bruijn, O,, Spence, R. and Chong, M.Y.: RSVP Browser: Web Browsing on Small Screen Devices. In Proceedings of Mobile HCI 2001, Lille, France (2001)

[19] Dey, A.K.:Understanding and Using Context. Personal and Ubiquitous Computing, Vol. 5. Springer-Verlag, London (2001) 4-7

[20] Dix, A., Rodden, T., Davies, N., Trevor, J., Friday, A. and Palfreyman, K.: Exploiting Space and Location as a Design Framework for Interactive Mobile Systems. Transactions on Computer-Human Interaction, Vol. 7, No. 3. ACM (2000) 285-321

[21] Dubois, E., Gray, P., and Nigay, L.: ASUR++: A Design Notation for Mobile Mixed Systems. In Proceedings of Mobile HCI 2002, Pisa, Italy, SpringerVerlag, Berlin (2002)

[22] Ebling, M.R., John, B.E. and Satyanarayanan, S.: The Importance of Transludence in Mobile Computing Systems. ACM Transactions on Computer-Human Interaction, Vol. 9, No. 1 (2002) 42-67

[23] Fano, A.: What are a Location's File and Edit Menus? Personal and Ubiquitous Computing, Vol. 5. Springer-Verlag, London (2001) 12-15

[24] Forlizzi, J. and McCormack, M.: Case Study: User Research to Inform the Design and Development of Integrated Wearable Computers and Web-Based Services. In proceedings of DIS 2000, ACM (2000)

[25] Fortunati, L.: The Mobile Phone: An Identity on the move. Personal and Ubiquitous Computing, Vol. 5. Springer-Verlag, London (2001) 85-98

[26] Frohlich, D. and Murphy, R.: The Memory Box. Personal and Ubiquitous Computing, Vol. 4. Springer-Verlag, London (2000) 238-240

[27] Geldof, S. and Terken, J.: Talking Wearables Exploit Context. Personal and Ubiquitous Computing, Vol. 5. Springer-Verlag, London (2001) 62-65

[28] Gelgon, M. and Tilhou, K. Automated Multimedia Diaries of Mobile Device Users Need Summarization. In Proceedings of Mobile HCI 2002, Pisa, Italy, Springer-Verlag, Berlin (2002)

[29] Goldstein, M., Oqvist, G., Bayat-M, M., Ljungstrand, P. and Bjork, S.: Enhancing the Reading Experience: Using Adaptive and Sonified RSVP for Reading on Small Displays. In Proceedings of Mobile HCI 2001, Lille, France (2001)

[30] Goldstein, M., Alsio, G. and Werdenhoff, J.: The Media Equation Does Not Always Apply: People are not Polite Towards Small Computers. Personal and Ubiquitous Computing, Vol. 6, Springer-Verlag, London (2002) 87-96

[31] Gonzalez-Castano, F.J., Anido-Rifon, L. and Costa-Montenegro, E.: A New Transcoding Technique for PDA Browsers, Based on Context Hierarchy. In Proceedings of Mobile HCI 2002, Pisa, Italy, Springer-Verlag, Berlin (2002)

[32] Green, N., Harper, R.H.R. and Cooper, G.: Configuring the Mobile User: Sociological and Industry Views. Personal and Ubiquitous Computing, Vol. 5. Springer-Verlag, London (2001) 146-156

[33] Hibino, S. and Mockus, A.: handiMessenger: Awareness-Enhanced Universal Communication for Mobile Users. In Proceedings of Mobile HCI 2002, Pisa, Italy, Springer-Verlag, Berlin (2002) 
[34] Hinckley, K., Pierce, J., Sinclair, M. and Horvitz, E.: Sensing Techniques for Mobile Interaction. In proceedings of UIST2000, San Diego, CA, USA, ACM (2000)

[35] Hinckley, K. and Horvitz, E.: Toward More Sensitive Mobile Phones. In proceedings of UIST2001, Orlando, Florida, USA, ACM (2001)

[36] Holland, S. and Morse, D.R.: AudioGPS: spatial audio in a minimal attention interface. In Proceedings of Mobile HCI 2001, Lille, France (2001)

[37] Holland, S., Morse, D. and Gedenryd, H.: Direct Combination: A New User Interaction Principle for Mobile and Ubiquitous HCI. In Proceedings of Mobile HCI 2002, Pisa, Italy, Springer-Verlag, Berlin (2002)

[38] Huang, E.M., Terry, M., Mynatt, E., Lyons, K. and Chen, A.: Distributing Event Information by Simulating Word-of-Mouth Exchanges. In Proceedings of Mobile HCI 2002, Pisa, Italy, Springer-Verlag, Berlin (2002)

[39] Huttenrauch, H. and Norman, M.: PocketCERO - mobile interfaces for service robots. In Proceedings of Mobile HCI 2001, Lille, France (2001)

[40] Isokoski, P. and Raisamo, R.: Device Independent Text Input: A Rationale and an Example. In Proceedings of AVI2000, Palermo, Italy, ACM (2000)

[41] Izadi, S., Fraser, M., Benford, S., Flintham, M, Greenhalgh, C., Rodden, T. and Schnadelbach, H.: Citywide: supporting interactive digital experiences across physical space. In Proceedings of Mobile HCI 2001, Lille, France (2001)

[42] James, C.L. and Reischel, K.: Text Input for Mobile Devices: Comparing Model Prediction to Actual Performance. In proceedings of CHI2001, Seattle, WA, USA, ACM (2001)

[43] Jameson, A.: Modeling both the Context and the User. Personal and Ubiquitous Computing, Vol. 5. Springer-Verlag, London (2001) 29-33

[44] Jones, M., Buchanan, G. and Thimbleby, H.: Sorting Out Searching on Small Screen Devices. In Proceedings of Mobile HCI 2002, Pisa, Italy, SpringerVerlag, Berlin (2002)

[45] Kehr, R. and Zeidler, A.: Look, Ma, My Homepage is Mobile! Personal and Ubiquitous Computing, Vol. 4. Springer-Verlag, London (2000) 217-220

[46] Kohtake, N., Rekimoto, J. and Anzai, Y.: InfoPoint: A Device that Provides a Uniform User Interface to Allow Appliances to Work Together over a Network. Personal and Ubiquitous Computing, Vol. 5. Springer-Verlag, London (2001) 264-274

[47] Lacucci, G., Kuutti, K. and Ranta, M.: On the Move with a Magic Thing: Role Playing in Concept Design of Mobile Services and Devices. In proceedings of DIS 2000, ACM (2000)

[48] Laerhoven, K.V. and Aidoo, K.: Teaching Context to Applications. Personal and Ubiquitous Computing, Vol. 5. Springer-Verlag, London (2001) 46-49

[49] Lamming, M., Eldridge, M., Flynn, M., Jones, C. and Pendlebury, D.: Satchel: Providing Access to Any Document, Any Time, Anywhere. Transactions on Computer-Human Interaction, Vol. 7, No. 3. ACM (2000) 322-352

[50] Lehikoinen, J. and Salminen, I.: An Empirical and Theoretical Evaluation of BinScroll: A Rapid Selection Technique for Alphanumeric Lists. Personal and Ubiquitous Computing, Vol. 6. Springer-Verlag, London (2002) 141-150 
[51] Licoppe, C. and Heurtin, J.P.: Managing One's Availability to Telephone Communication Through Mobile Phones: A French Case Study of the Development of Dynamics of Mobile Phone Use. Personal and Ubiquitous Computing, Vol. 5. Springer-Verlag, London (2001) 99-108

[52] Lin, J., Laddaga, R. and Naito, H.: Personal Location Agent for Communicating Entities (PLACE). In Proceedings of Mobile HCI 2002, Pisa, Italy, SpringerVerlag, Berlin (2002)

[53] Ling, R.: We Release Them Little by Little: Maturation and Gender Identity as Seen in the Use of Mobile Telephony. Personal and Ubiquitous Computing, Vol. 5. Springer-Verlag, London (2001) 123-136

[54] Ljungstrand, P.: Context Awareness and Mobile Phones. Personal and Ubiquitous Computing, Vol. 5. Springer-Verlag, London (2001) 58-61

[55] MacKenzie, I.S., Kober, H., Smith, D., Jones, T. and Skepner, E.: LetterWise: Prefix-Based Disambiguation for Mobile Text Input. In proceedings of UIST2001, Orlando, Florida, USA, ACM (2001)

[56] MacKenzie, S.: KSPC (Keystrokes per Character) as a Characteristic of Text Entry Techniques. In Proceedings of Mobile HCI 2002, Pisa, Italy, SpringerVerlag, Berlin (2002)

[57] Mantyjarvi, J. and Seppanen, T.: Adapting Applications in Mobile Terminals Using Fuzzy Context Information. In Proceedings of Mobile HCI 2002, Pisa, Italy, Springer-Verlag, Berlin (2002)

[58] Marsden, G., Thimbleby, H., Jones, M. and Gillary, P.: Data Structures in the Design of Interfaces. Personal and Ubiquitous Computing, Vol. 6. SpringerVerlag, London (2002) 132-140

[59] Matsushita, N., Ayatsuka, Y. and Rekimoto, J.: Dual Touch: A Two-Handed Interface for Pen-Based PDAs. In proceedings of UIST2000, San Diego, CA, USA, ACM (2000)

[60] Mayol, W.W., Tordoff, B.J. and Murray, D.W.: Wearable Visual Robots. Personal and Ubiquitous Computing (2002), Vol. 6. Springer-Verlag, London (2002) 37-48

[61] Mizobuchi, S., Mori, K., Ren, X. and Michiaki, Y.: An Empirical Study of the Minimum Required Size and the Minimum Number of Targets for Pen Input on the Small Display. In Proceedings of Mobile HCI 2002, Pisa, Italy, SpringerVerlag, Berlin (2002)

[62] Mikkonen, M., Vayrynen, S., Ikonen, V. and Heikkila, O.: User and Concept Studies as Tools in Developing Mobile Communication Services for the Elderly. Personal and Ubiquitous Computing (2002), Vol. 6. Springer-Verlag, London (2002) 113-124

[63] Milewski, A. and Smith, T.M.: Providing Presence Cues to Telephone Users. In Proceedings of CSCW2000, Philadelphia, PA, USA, ACM (2000)

[64] Nakanishi, Y., Tsuji, T., Ohyama, M. and Hakozaki, K.: Context Aware Messaging Service: A Dynamical Messaging Delivery using Location Information and Schedule Information. Personal and Ubiquitous Computing (2000), Vol. 4. Springer-Verlag, London (2000) 221-224 
[65] Nigay, L., Salembier, P., Marchand, T., Renevier, P. and Pasqualetti, L.: Mobile and Collaborative Augmented Reality: A Scenario Based Design Approach. In Proceedings of Mobile HCI 2002, Pisa, Italy, Springer-Verlag, Berlin (2000)

[66] Oquist, G. and Goldstein, M.: Towards an Improved Readability on Mobile Devices: Evaluating Adaptive Rapid Serial Visual Presentation. In Proceedings of Mobile HCI 2002, Pisa, Italy, Springer-Verlag, Berlin (2002)

[67] Palen, L., Salzman, M. and Youngs, E.: Going Wireless: Behavior \& Practice of New Mobile Phone Users. In Proceedings of CSCW2000, Philadelphia, PA, USA, ACM (2000)

[68] Palen, L., Salzman, M. and Youngs, E.: Discovery and integration of Mobile Communications in Everyday Life. Personal and Ubiquitous Computing, Vol. 5. Springer-Verlag, London (2001) 109-122

[69] Palen, L. and Salzman, M.: Beyond the Handset: Designing for Wireless Communication Devices. Transactions on Computer-Human Interaction, Vol. 9, No. 2. ACM (2002) 125-151

[70] Partridge, K., Chatterjee, S. and Want, R.: TiltType: Accelerometer-Supported Text Entry for Very Small Devices. In proceedings of UIST2002, Paris, France, ACM (2002)

[71] Pascoe, J., Ryan, N. and Morse, D.: Using While Moving: HCI Issues in Fieldwork Environments. Transactions on Computer-Human Interaction, Vol. 7, No. 3. ACM (2000) 417-437

[72] Perry, M., O'Hara, K., Sellen, A., Brown, B. and Harper, R.: Dealing with Mobility: Understanding Access Anytime, Anywhere. Transactions on ComputerHuman Interaction, Vol. 8, No. 4. ACM (2001) 323-347

[73] Petrelli, D., Not, E., Zancanaro, M., Strapparava, C. and Stock, O.: Modeling and Adapting to Context. Personal and Ubiquitous Computing, Vol. 5. Springer-Verlag, London (2001) 20-24

[74] Pham, T., Schneider, G., Goose, S. and Pizano, A.: Composite Device Computing Environment: A Framework for Situated Interaction Using Small Screen Devices. Personal and Ubiquitous Computing, Vol. 5. Springer-Verlag, London (2001) 25-28

[75] Pirhonen, A., Brewster, S. and Holguin, C.: Gestural and Audio Methaphors as a Means of Control for Mobile Devices. In Proceedings of CHI2002, Minneapolis, Minnesota, USA, ACM (2002)

[76] Pospischil, G., Umlauft, M. and Michlmayr, E.: Designing LoL@, a Mobile Tourist Guide for UMTS. In Proceedings of Mobile HCI 2002, Pisa, Italy, Springer-Verlag, Berlin (2002)

[77] Poupyrev, I., Maruyama, S. and Rekimoto, J.: Ambient Touch: Designing Tactile Interfaces for Handheld Devices. In proceedings of UIST2002, Paris, France, ACM (2002)

[78] Raghunath, M.T., Narayanaswami, C.: User Interfaces for Application s on a Wrist Watch. Personal and Ubiquitous Computing, Vol. 6. Springer-Verlag, London (2002) 17-30

[79] Randell, C. and Muller, H.: The Shopping Jacket: Wearable Computing for the Consumer. Personal and Ubiquitous Computing, Vol. 4. Springer-Verlag, London (2000) 241-244 
[80] Randell, C. and Muller, H.L.: The Well Mannered Wearable Computer. Personal and Ubiquitous Computing, Vol. 6. Springer-Verlag, London (2002) 3136

[81] Rantanen, J., Impio, J., Karinsalo, T., Reho, A., Tasanen, M. and Vanhala, J.: Smart Clothing Prototype for the Artic Environment. Personal and Ubiquitous Computing, Vol. 6. Springer-Verlag, London (2002) 3-16

[82] Ren, X., Moriya, S.: Improved Selection Performance on Pen-Based Systems: A Study of Pen-Based Interaction for Selection tasks. Transactions on Computer-Human Interaction, Vol. 7, No. 3. ACM (2000) 384-416

[83] Rist, T., Brandmeier, P., Herzog, G. and Andre, E.: Getting the Mobile Users in: Three Systems that Support Collaboration in an Environment with Heterogeneous Communication Devices. In Proceedings of AVI2000, Palermo, Italy, $\operatorname{ACM}(2000)$

[84] Rist, T., and Brandmeier, P.: Customizing Graphics for Tiny Displays of Mobile Devices. In Proceedings of Mobile HCI 2001, Lille, France (2001)

[85] Ross, D.A. and Blasch, B.B.: Development of a wearable Computer Orientation System. Personal and Ubiquitous Computing, Vol. 6. Springer-Verlag, London (2002) 49-63

[86] Roth, J. and Unger, C.: Using Handheld Devices in Synchronous Collaborative Scenarios. Personal and Ubiquitous Computing, Vol. 5. Springer-Verlag, London (2001) 243-252

[87] Roth, J.: Patterns of Mobile Interaction. In Proceedings of Mobile HCI 2001, Lille, France (2001)

[88] Ruuska-Kalliokulja, S., Schneider-Hufschmidt, M., Vaananen-Vainio-Mattila, K. and Von Niman, B.: Shaping the future of Mobile Devices - Results of the CHI2000 Workshop on Future Mobile Device User Interfaces. In Proceedings of Mobile HCI 2001, Lille, France (2001)

[89] Sawhney, N. and Schmandt, C.: Nomadic Radio: Speech and Audio Interaction for Contextual Messaging in Nomadic Environments". Transactions on Computer-Human Interaction, Vol. 7, No. 3. ACM (2000) 353-383

[90] Sazawal, V., Want, R. and Boriello, G.: The Unigesture Approach: OneHanded Text Entry for Small Devices. In Proceedings of Mobile HCI 2002, Pisa, Italy, Springer-Verlag, Berlin (2002)

[91] Schenkman, B.N.: Perceived Similarities and Preferences for Consumer Electronics Products. Personal and Ubiquitous Computing, Vol. 6. Springer-Verlag, London (2002) 125-131

[92] Schmidt, A., Takaluoma, A. and Mantyjarvi, K.: Context-Aware Telephony Over WAP. Personal and Ubiquitous Computing, Vol. 4. Springer-Verlag, London (2000) 225-229

[93] Schmidt, A., Stuhr, T. and Gellersen, H.: Context-Phonebook - Extending Mobile Phone Applications with Context. In Proceedings of Mobile HCI 2001, Lille, France (2001)

[94] Sharples, M., Corlett, D. and Westmancott, O.: The Design and Implementation of a Mobile Learning Resource. Personal and Ubiquitous Computing (2002) Vol. 6. Springer-Verlag, London (2002) 220-234 
[95] Silfverberg, M., Mackanzie, I.S. and Korhonen, P.: Predicting Text Entry Speed on Mobile Phones. In Proceedings of CHI2000, The Hague, Amsterdam, ACM (2000)

[96] Strom, G.: Mobile Devices as Props in Daily Role Playing. In Proceedings of Mobile HCI 2001, Lille, France (2001)

[97] Swindells, C., Inkpen, K.M., Dill, J.C. and Tory, M.: That one There! Pointing to establish device identity. In proceedings of UIST2002, Paris, France, ACM (2002)

[98] Tang, J., Yankelovich, N., Begole, B., Van Kleek, M., Li, F. and Bhalodia, J.: ConNexus to Awarenex: Extending awareness to mobile users. In proceedings of CHI2001, Seattle, WA, USA, ACM (2001)

[99] Thomas, B., Grimmer, K., Zucco, J. and Milanese, S.: Where Does the Mouse Go? An Investigation into the Placement of a Body-Attached TouchPad Mouse for Wearable Computers. Personal and Ubiquitous Computing, Vol. 6. Springer-Verlag, London (2002) 97-112

[100] Trevor, J., Hilbert, D.M., Schilit, B.N. and Koh, T.K.: From Desktop to Phonetop: A UI For Web Interaction On Very Small Devices. In proceedings of UIST2001, Orlando, Florida, USA, ACM (2001)

[101] Weilenmann, A.: Negotiating Use: Making Sense of Mobile Technology. Personal and Ubiquitous Computing, Vol. 5. Springer-Verlag, London (2001) 137145

[102] Wobbrock, J.O., Forlizzi, J., Hudson S.E. and Myers, B.A.: WebThumb: Interaction Techniques for Small-Screen Browsers. In proceedings of UIST2002, Paris, France, ACM (2002) 